\title{
Joint actions may hold the vital formula
}

Is the United States ready to cut its carbon emissions, as the rest of the world demands? Not a chance. Are the poor countries ready to promise to cap their own emissions, as the US Senate is demanding? No way. Is the Kyoto meeting therefore heading for abject failure? Not necessarily.

The differences between the two sides could be accommodated. And experts agree that the essence of any such accommodation will be the practices known as 'joint implementation' and emissions trading.

'Joint implementation' is the term used by economists to describe projects carried out by the rich countries in poor countries in order to help meet the former's targets for reducing greenhouse gas emissions.

Instead of slapping five cents on the price of a gallon of gasoline, for example, the United States could attempt to meet its own reduction targets by helping to construct a hydro-electric scheme in Guatemala, alleviating the need for that country to generate electricity by burning fossil fuel.

Under the related concept of emissions trading, governments - or even corporations - could buy and sell emissions credits. If Japan could not meet its own emissions goal, for example, it would be able to buy 'credits' from a nation such as Russia that was on course to meet its target.

Economists believe that such a market would redistribute emission cuts to wherever costs are lowest. Indeed, trading in emis- sions of sulphur dioxide has been tried out between corporations in the United States, and has been highly successful in reducing the costs of cutting pollution.

But vast obstacles remain to the use of either joint implementation or emissions trading in a global scheme to cut greenhouse gas emissions. In the case of joint implementation, a programme of pilot schemes introduced as part of the 1995 Berlin mandate has so far achieved little.

Europe and the poor countries want the pilot programme to continue for a couple of years on its current basis. But the United States believes that the scheme has been slow to take off because it does not give participants any 'credits' against their own emissions targets - and wants it reformed to do precisely that.

Joint implementation need not only give credits to the rich, donor country, but could do so to the poor, recipient nation as well. But many poor countries don't want that, as it would imply their acceptance of the need for caps on their own emissions. "They see joint implementation as the start of a slippery slope" towards accepting caps, says one diplomat.

According to Bob Dickson, head of the US government's joint implementation office, "We'd like to end the pilot phase and get an agreement for joint implementation with crediting to all parties." But after two years of trying, the United States has only won the support of Costa Rica, and possibly Argentina, for its vision of joint implementation.

Emissions trading is, if anything, even more fraught. A trading regime would probably be limited at first to those rich countries - the United States, western Europe and Japan - that have the legal and technical equipment to monitor emissions and implement a trading scheme.

Trading could occur at two levels: between nations, and between corporations within each nation. The latter would be relatively straightforward in countries with competitive, private-sector energy markets, such as the United States.

But any global scheme would be far more complex, as it would require global policing. Commentators such as Ed Parson, a specialist in emissions trading at Harvard University's John F. Kennedy School of Government, point out that sulphur dioxide trading only works in the United States because the powerful Environmental Protection Agency is there to enforce it.

Some critics also ask who would prevent governments from interfering with the market to defend their regional and national interests.

Trading would "require governments to relinquish a huge amount of power," says Parson. "International trading is the way to go - but it is naive to think that we have worked out how to do it."

c.M.

\section{What to look for at Kyoto}

The United Nations Framework Convention on Climate Change opened for signature at the 1992 Earth Summit in Rio de Janeiro, at which countries agreed to reduce their emissions to 1990 levels by 2000 (a goal that now appears highly unlikely to be achieved). The convention was strengthened three years later at a meeting in Berlin at which signatories agreed not to require new commitments from developing countries. At Kyoto, the plan is to go further and set legally binding targets for the period beyond 2000.

\section{- The Alliance of Small Island States}

The oldest, most ambitious and - politically - least realistic target is that proposed by the 42-member Alliance of Small Island States. With the most to lose from rising sea levels, member countries want strong action, and fast. This has translated into demands for a 20 per cent reduction in greenhouse gas emissions from 1990 levels by 2005.

\section{- The European Union}

The 15 member states of the European Union have agreed to propose a 15 per cent reduction from 1990 levels by 2010 for all developed countries. The EU has also proposed an interim target of a minimum 7.5 per cent reduction in emissions by 2005 . Reductions will be made to a 'basket' of three gases: carbon dioxide, methane and nitrous oxide.

The ingenuity of the EU proposal is its 'bubble' approach, averaging out member states' emissions. This would allow poorer member states to increase their emissions as richer states cut down more than the average. It also accommodates France, which is keen only to stablilize its emissions at 1990 levels on the grounds that they are already relatively low because it relies largely on nuclear power rather than fossil fuels.

\section{- The United States}

The United States will go to Kyoto with one of the weakest proposals on emissions targets - a promise merely to stabilize at 1990 levels by between 2008 and 2012, with a further unspecified cut by 2017. But administration officials point out that even stabilization at 1990 levels would amount to a 15 per cent cut 
for the United States from present levels and that emissions are continuing to rise.

In addition, US officials want 'meaningful' participation from major developing countries, including a willingness to participate in emissions trading and joint implementation. Observers believe that the United States may possibly relax its stance on targets slightly in the closing stages of the meeting if some of its other conditions are met.

\section{- Japan}

Japan has taken much flak for its proposal to reduce emissions by 5 per cent from between 2008 and 2012 for a three-gas basket of carbon dioxide, methane and nitrous oxide. But this proposal could well emerge as the only realistic outcome at Kyoto. If so, Japan's

much-maligned 'softly, softly' consensual approach to the negotiations will have been vindicated, and its first foray as host of a major international agreement deemed a success.

As the host of the meeting, Japan has been pilloried by some for not showing more leadership. But Japanese officials are in close and constant touch with Washington and major European and G77 capitals. It is therefore little surprise that their proposal neatly falls between those backed by the first two, while incorporating some of the demands of the G77.

Japan's proposal includes elements of other demands, such as lower targets for countries with low population growth and low incomes per head. The proposal also

\section{Obstacles to an agreement}

Success at Kyoto will need agreement on a method of calculating emissions reductions. The United States favours what has become known as the 'net' approach. According to this method, a country's inventory of 'man-made' carbon emissions will include carbon released into the atmosphere from the clearing of forests. It will also take account of carbon removed from the atmosphere from, for example, the planting of trees. This is controversial, partly because it is not clear how this carbon will be calculated.

Another issue will be the 'basket' versus the 'gas-by-gas' method of calculating emissions. The European Union supports the idea that reductions should be made collectively to a basket of three gases: carbon dioxide, methane and nitrous oxide. But environmentalist groups oppose this on the grounds that it would allow countries to make disproportionate reductions to methane and nitrous oxide, in comparison to carbon dioxide, which constitutes 80 per cent of developed country greenhouse gas emissions.

Also at issue will be the period over which reductions can be made. Some countries - the United States again would like five years to reduce emissions. Others want specific annual targets.

Finally there is the crucial question of which 'legal instrument' to use. If countries do agree on targets, the climate convention will need to be changed. The change could take the form of an amendment to the convention. This will require signatures from at least three-quarters - more than 120 - of the countries which have signed and ratified the convention. But the amendment will not enter into force - the point at which emissions targets become legally binding - until all these countries have ratified the change to the convention in their national parliaments. This is not expected to happen before 2010 .

The alternative method of changing the convention is through what is known as a 'protocol'. The main advantage of a protocol over an amendment is that countries have more freedom to decide when it enters into force. They can, for example, decide entry into force after it has been ratified in the national parliaments of, for example, just 50 countries. But a protocol's drawback is that it needs a consensus of all the parties. In other words, a single, dissenting country can veto the whole process.

European government lawyers anticipated this potential difficulty nearly a year ago, and have tabled an advance amendment to the convention which says that a protocol should be allowed to be adopted at Kyoto by a three-quarters majority vote. This is a high-risk strategy and bound to be opposed by countries such as Saudi Arabia and Australia. "When you've got 48 hours to go [at Kyoto], everyone's dead tired, and one country is blocking progress, the chairman will need to pull a rabbit of the bag," says one government

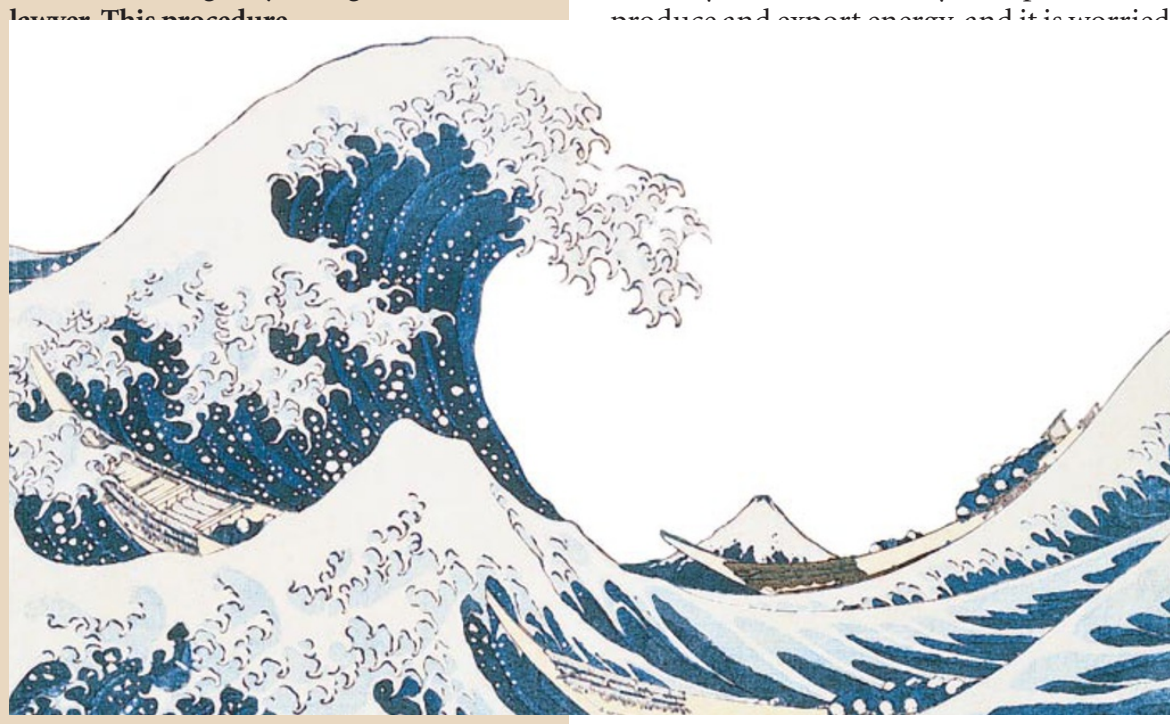

calls on 'advanced' developing countries to assume voluntary commitments.

\section{- Developing countries}

The Group of 77 developing countries tried to scoop the US proposal last month by tabling their own proposal hours before Clinton's announcement. The G77 proposal is a slightly modified version of that from the European Union: it suggests that targets be set for individual gases, not a basket of three, and achieved domestically, without emissions trading or joint implementation. The group also wants a 35 per cent reduction in emissions by 2020 .

The G77 proposal includes a demand for a compensation fund for 'economic impacts' of climate change policies. This demand spans a variety of interests, from those of the oil-producing states, which want to be compensated for revenues from lost oil sales, to those of the small island states, which want compensation if they suffer because of delays in international action.

\section{- Brazil}

One of the most sophisticated proposals comes from Brazil. Largely the work of Gylvan Meira, head of the Brazilian Space Agency, it suggests that targets be based on historical emissions; in other words, that those countries that began to emit carbon dioxide from the beginning of the Industrial Revolution should reduce the most, and vice versa. It also includes penalties for countries which overshoot their targets, to be paid into a fund to finance clean technology projects in the developing world.

\section{- Australia}

Australia is one of the few countries to have publicly declared its opposition to legally binding targets, despite appearing to be brought into line last month at the Commonwealth Heads of Government meeting (see Nature 389, 893; 1997). Australia's industry is dominated by companies that 